\title{
Plastic Instability of the C35 Steel under Mechanical Surface Treatment Effect
}

\author{
Hamadache Hamid ${ }^{1, *}$, Zemouri Zahia ${ }^{2}$, Touati Ramdane ${ }^{1}$, Serge Dominiak ${ }^{3}$ \\ ${ }^{1}$ Advanced Technologies in Mechanical Production Research Laboratory (LRATPM), Badji Mokhtar Annaba University, Algeria \\ ${ }^{2}$ Department of Mechanical Engineering, Badji Mokhtar University, Annaba, Algeria \\ ${ }^{3}$ University of Lorraine, the Laboratory of study of microstructures, mechanics and material sciences (LEM3), France
}

Copyright $\bigcirc 2016$ by authors, all rights reserved. Authors agree that this article remains permanently open access under the terms of the Creative Commons Attribution License 4.0 International License

\begin{abstract}
Burnishing is a mechanical surface treatment (MST) that implements a plastic deformation of the surface layers of materials and modifies their basic properties. A comparative study between the tensile properties resulting from machining and burnishing states was conducted. By modeling the stress-strain curves, the work hardening coefficient of the material was evaluated to better appreciate the field of plastic instability for both conditions. A simulation of the tensile test performed by the Abaqus software was used to visualize the phenomenon of plastic instability between the onset of necking and the fracture. The simulation results are in good correlation with those of experiment.
\end{abstract}

Keywords Steel C35, Ball-burnishing, Tensile Test; Hardening, Plastic Instability

\section{Introduction}

Mechanical surface treatment (MST) are often performed to obtain the desired surface properties and to enhance the mechanical strength of materials. Moreover, they are important aspect of all manufacturing processes. One of the most effective processes is the burnishing [1-3]. This method of surface plastic deformation (SPD) is a surface finishing technique in which hardened, highly polished steel ball or diamond tip are brought into pressure contact with a softer piece part. As the pressure generated through the active part exceeds the yield point of the piece-part material, the surface is plastically deformed by cold flowing of sub-surface material. The described method (Burnishing) also contributes to the formation of hard surface layers which acquire special characteristics, while, due to previous machining processes [4-6]. These primary benefits of the burnishing process lead to improve the resistance of material. For instance, it is shown that the true stress of $\mathrm{O} 1$ steel has been increased of about $150 \mathrm{MPa}$, the surface quality has been enhanced by $12.5 \%$, and finally the ultimate tensile stress has been increased by $166 \mathrm{MPa}$ [7]. With an optimum force of $300 \mathrm{~N}$ for burnishing AISI 1010 steels plates. It is noted an improvement in elongation up to $49 \%$ [8]. For the treatment on aluminum $1050 \mathrm{~A}$, it is found that burnishing improved its ductility, but not its microhardness [9].

It is shown that the material loses a very small amount of energy during the majority of its life and keeps its ductility. This loss of ductility is more and more increased when the material is stressed in tension after having undergone a number of fatigue cycles [10]. In conventional tensile testing, plastic instability occurs just after the maximum load (ultimate tensile stress Rm). At this point, strain localization starts by diffuse necking that may continue up to fracture or until the development of a localized neck, which then leads to fracture. The most widely used constitutive equations for representing the plastic material behavior are Hollomon, Swift, Ludwik. Recently, new hardening function that combines Swift and Holloman law was proposed in Ref. 11, true stress-true strain curve for the post-necking regime of different aerospace alloys was extrapolated using the weighted average method.

The purpose of the current study was to investigate the effect of the process on the strain-hardening and the tensile properties of burnished Steel C35. The total strain in the plastic instability threshold has been analyzed to highlight the influence of the process, to compare and assess the benefits compared to conventional turning.

\section{Material and Techniques}

\subsection{Material}

In this study, Steel C35 (according the standard NF EN 10027-1) with chemical composition : $(0.35-0.40) \% \mathrm{C}$; $(0.10-0.35) \% \mathrm{Si} ;(0.50-0.80) \% \mathrm{Mn} ; 0.035 \% \mathrm{P} ; 0.025 \% \mathrm{Si}$ was used as work-piece material. Steel C35 received in the form of cylindrical rod was selected because of its machinability and its range of applications in the industry. 
The mechanical properties of the material were assessed using monotonic tension tests on cylindrical specimens. The tensile testing machine used is a universal machine MFL type VHP 600 Zwick with $600 \mathrm{kN}$ force transducer and displacement rate range from 1 to $300 \mathrm{~mm} / \mathrm{min}$. Tests were performed at room temperature. Data acquisition system of the tensile testing machine system was performed in Zwick Z1011 software.

The specimens were machined according to the standard NF EN 10002-1. All specimens were machined from the same batch to minimize possible deviation in experimental data. Before the tensile test, the specimens have according to the case been undergone an appropriate burnishing treatment or remaining with machining state. The tensile test offers an overall response of the material. In order to better predicting the distribution of stresses vs strain at the local scale in the necking zone, a FEM simulation of the tensile test was performed using the commercial software Abaqus.

\subsection{Burnishing}

A burnishing tool (Fig. 1a) with interchangeable adapter for diamond ball with different radius (r) were designed and fabricated for the purpose of the experimental tests.

Fig. $1 \mathrm{~b}$ shows a schematic representation of the burnishing tool in which a body is to be firmly clamped on the lathe machine. A helical compression spring is used to exert the burnishing force $(\mathrm{P})$ on the piece animated with a rotation movement $(\mathrm{N})$ during burnishing operations. The burnishing feed rate $(\mathrm{f})$ is assigned to the tool which operates according to a number of passes (i). A calibration process was conducted using the actual burnishing operation setting to obtain a relationship between the burnishing force and the corresponding axial displacement. Burnishing parameters considered are: $\mathrm{N}=560$ rev. $\mathrm{min}^{-1} ; \mathrm{f}=0.054 \mathrm{~mm} \cdot \mathrm{rev}^{-1} ; \mathrm{P}=20$ $\mathrm{kgf} ; \mathrm{r}=2 \mathrm{~mm}$ and $\mathrm{i}=3$ passes.

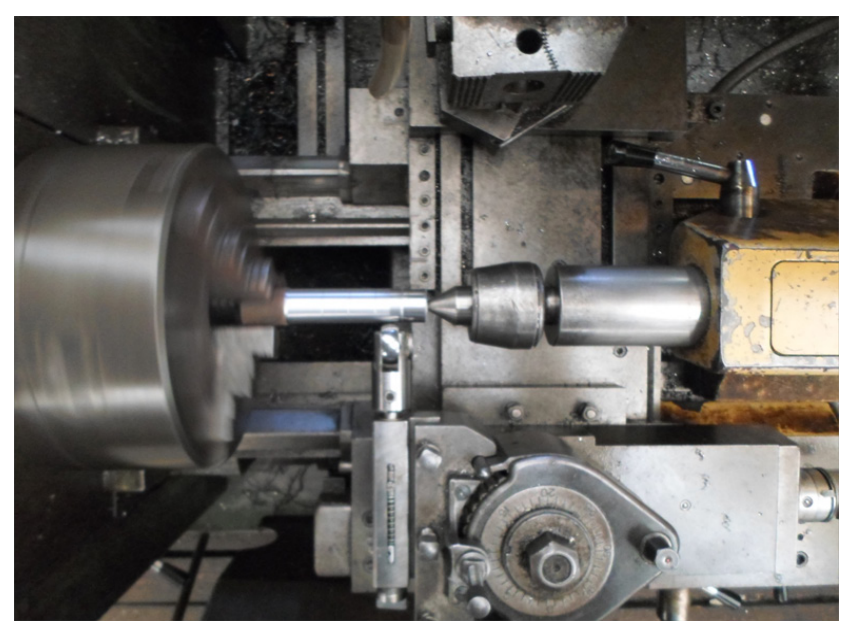

(a)

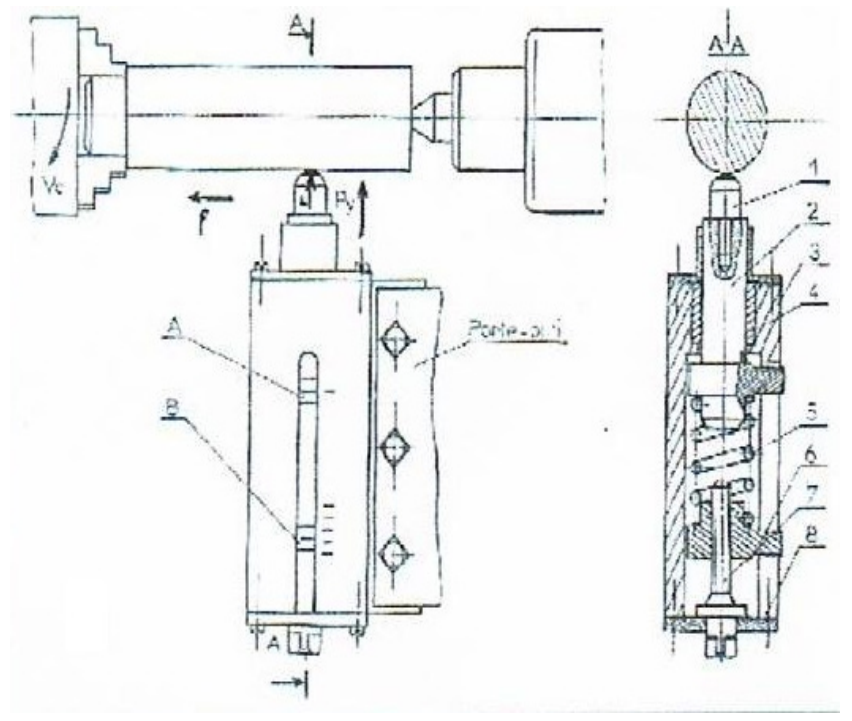

(b)

Figure 1. Burnishing a) Photograph of the tool clamped on the lathe machine, b) view of tool assembly

\section{Experimental Results}

Tensile tests allowed plotting the conventional curves (Fig. 2a) and showing the following mechanical characteristics (Tab. 1).

Table 1. Mechanical properties of steel C35

\begin{tabular}{lccc}
\hline Treatment & $\mathrm{R}_{\mathrm{e}}(\mathrm{MPa})$ & $\mathrm{R}_{\mathrm{m}}(\mathrm{MPa})$ & $\mathrm{A} \%$ \\
\hline Turning & 452.1 & 655.8 & 23.53 \\
\hline load-dumps at $500 \mathrm{MPa}$ & 506.4 & 628.2 & 21.89 \\
\hline Burnishing & 415.7 & 643.0 & 22.66 \\
\hline
\end{tabular}

The work-hardening of material has been demonstrated by the study of loops "load-dumps" in the plastic range $(\sigma=500$ $\mathrm{MPa}$ ). Hence the stress is relaxed slowly to zero; we reload the specimen and the new yield strength is observed (linearity) of the new curve Fig. 2b.

The curves reflect clearly an elastoplastic behavior that reveals both classic areas of such behavior. The slope of the linear part is the same regardless of the type of treatment that is to say, the material keeps its rigidity. 

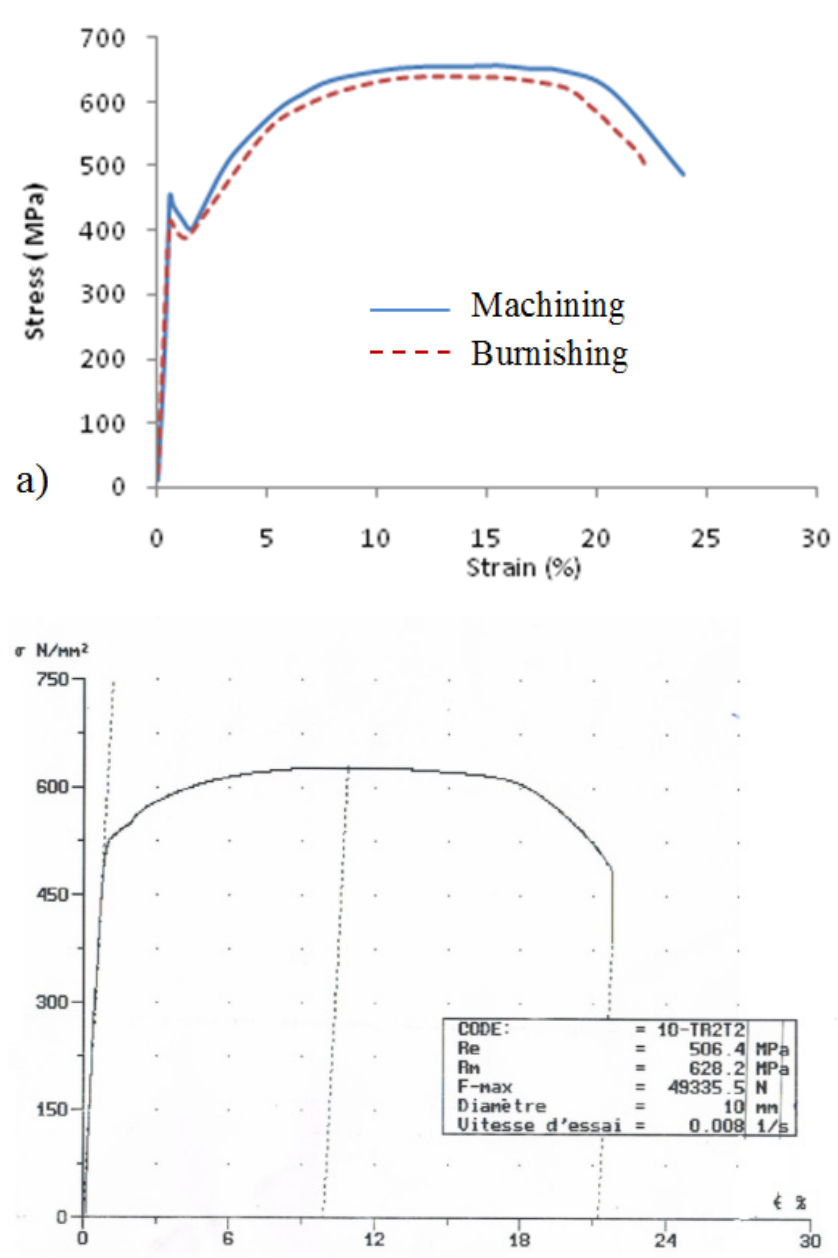

(b)

Figure 2. Stress-strain curves of steel $\mathrm{C} 35$, a) Conventional curves, b) After dumps from $500 \mathrm{MPa}$

\section{Discussion}

Although at first loading, the tests are identical from the standpoint of material, geometry and test condition, we noticed that the two acquired engineering curves relating to the machined and burnished specimens presented a disturbance at the yield strength (Re) level, is that the material has a higher and a lower yield strength.

No disturbance is marked when reloading material and stress strain curve (Fig. 2b) changes continuously until fracture. During the tensile test, the specimen is subjected to two influences: The hardening that tends to consolidate and the necking that tends to reduce the section and weaken it. As hardening prevails, deformation remains homogeneous. As soon as the weakening prevails, there is instability because then the deformation is localized in the weakened area of the specimen, and there are then necking. Fig. 3 shows the effect of the charge-discharge on the tensile properties of C35 steel.

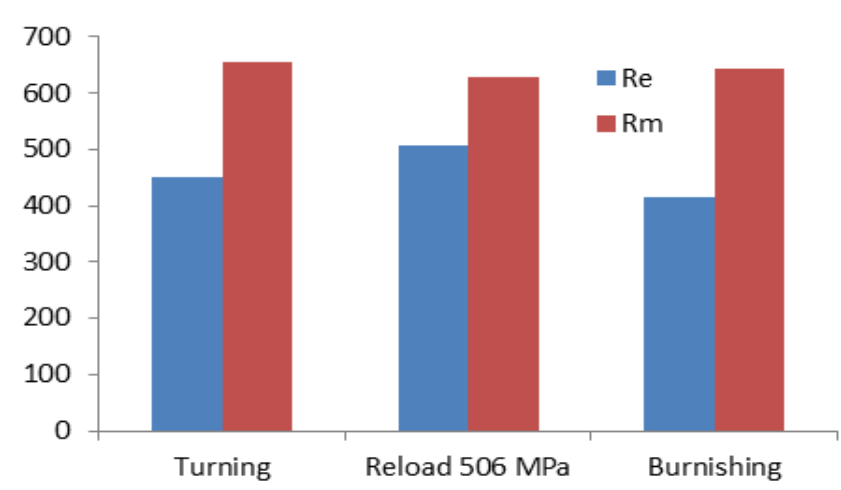

(a)

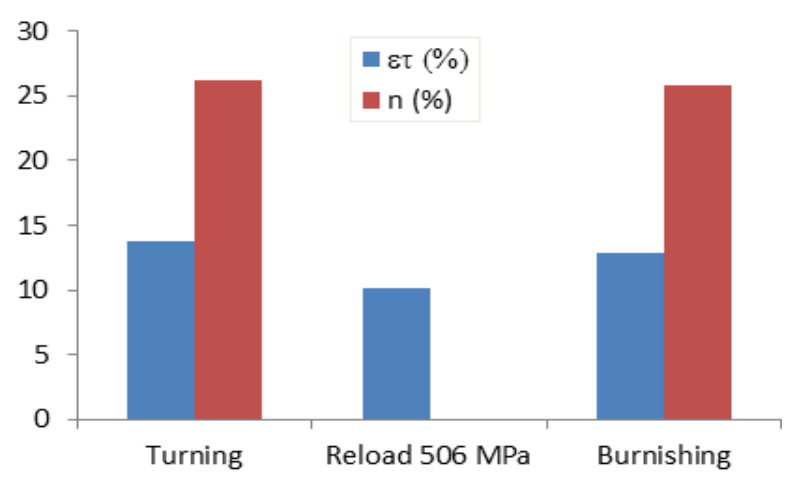

(b)

Figure 3. Tensile properties of the $\mathrm{C} 35$ steel for different treatments. a) $\mathrm{Re}$ and $\mathrm{Rm}, \mathrm{b}$ ) work hardening coefficient (n) and total Strain $\left(\varepsilon_{\mathrm{t}}\right)$ to the plastic instability threshold

After stress relaxation and recharge commissioning, material behavior is linear up to a stress level of about 506 $\mathrm{MPa}$. That is to say, the yield strength has been increased and the material has been hardened (Fig. 3a). This consolidation has resulted in a slight decrease in the ultimate tensile stress $(\mathrm{Rm})$ and shortening of the field of work hardening at the expense of starting the instability that started less than $13.67 \%$ (Fig. 3b).

\subsection{Burnishing Effect on Tensile Properties.}

Fig. 3a shows the effect of burnishing on the main tensile properties of $\mathrm{C} 35$ steel. Burnishing has not given its beneficial effects with respect to the work-hardening of the material. One notices a reduction of $8.05 \%$ of the yeld stress and a $1.95 \%$ of tensile strength. The material seems to undergo a softening phenomenon. In this case; while lower strain rates will produce work hardening increasing the hardness of the material, under extremely high strain levels and a long rest the viscosity decreases. The material is shearbreak downed and exhibit a gradual decrease in the hardness, the yield strength, ultimate tensile strength, and percent elongation at fracture [9]. 
In the machining state, the $\mathrm{C} 35$ steel undergoes a deformation of $13.761 \%$ before becoming plastically unstable. At the burnishing state, the onset of necking occurred early with at strain rate of $12.89 \%$ (Fig. 3b). This has narrowed the field of development of necking.

\subsection{Burnishing Effect on the Work Hardening Coefficient}

In conventional tensile testing, plastic instability occurs just after the maximum load. Up to the maximum load, In order to develop an accurate analytical model, the engineering stress-strain data was converted to true stress-strain values. The basic conservation of volume law was used for this operation. The most widely used constitutive equations for representing the plastic material behavior is Ludwik law (Eq. 1).

$$
\sigma_{\mathrm{v}}=\sigma_{0}+\mathrm{k}\left(\varepsilon_{\mathrm{r}}\right)^{\mathrm{n}}
$$

By linearizing this equation, the slope of the curve in logarithmic coordinates is the work hardening coefficient (n) which characterizes the ability of the material to undergo plastic deformation and transmit throughout the volume of material. Fig. 3b shows that this coefficient (n) intrinsic of the material dropped from 0.2614 at machining state until 0.2582 at the burnishing state. This drop of about $1.2 \%$ may be a consequence of the decrease of $\mathrm{Re}$ and $\mathrm{Rm}$ after burnishing.

\subsection{Simulation of Tensile Test}

The mechanical properties for the material and the behavior before and after necking were observed with simulation and then compared with the experimental data. The method utilizes a FE model of the tensile test and allows obtaining the predicted load-displacement results.

The simulation of the tensile test was performed in the Abaqus software. The fixing tooling of the specimen was considered as a rigid body in the model. In the FE model, one end of the specimen was fixed, and the displacement was applied to the opposite end to simulate an actual tensile test procedure performed under displacement control. To concentrate the strain in a necking zone in the center of the useful part of the specimen, the boundary conditions make that the anchoring heads are not solicited. A mesh size study was performed and for each increment, the stress-strain behavior for material was calculated and plotted. Gradually, as the stresses evolve along the series of nodes at each increment of the tensile test (Fig. 4a), the deformation is concentrated progressively toward the nodes of the center of the specimen. The simulation showed a reduction in the cross section, mimicking the onset of necking.

The digital display shows indeed that the nodes of the ends of the specimen are discharged at each increment to allow a localized necking (Fig. 4b) before final fracture of the material. This finding corresponds exactly to that observed during the experimental testing.

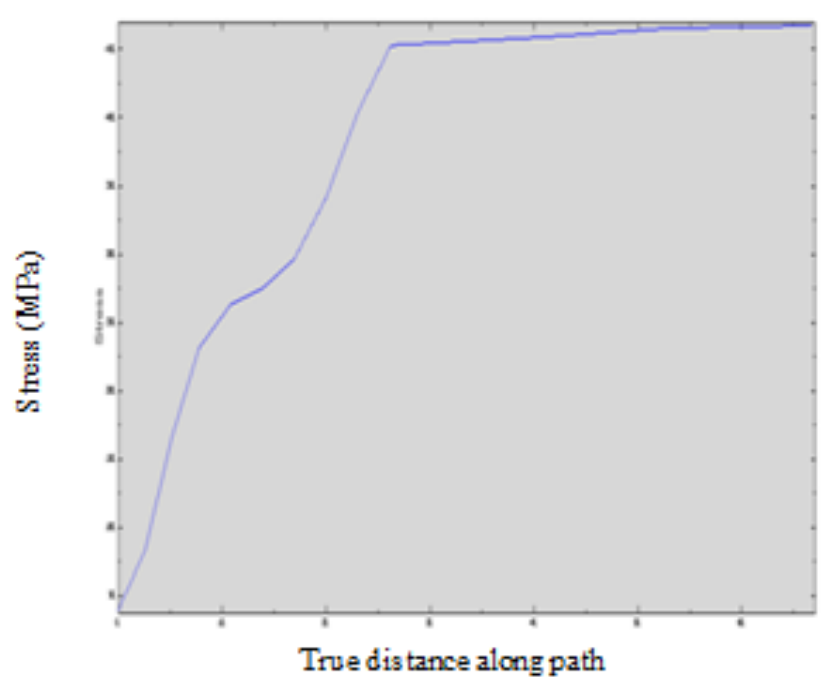

(a)

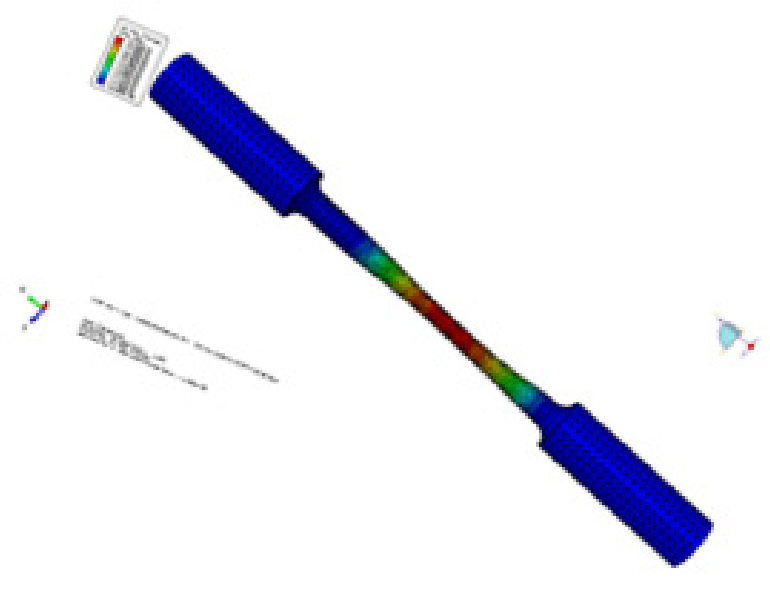

(b)

Figure 4. Tensile testing simulation: a) Stress in the nodes, b) Necked specimen

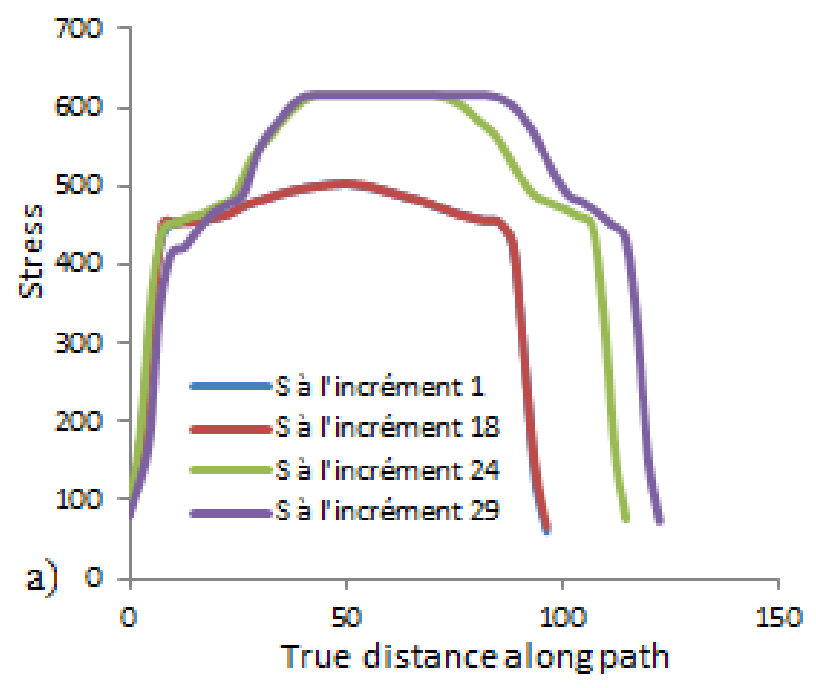




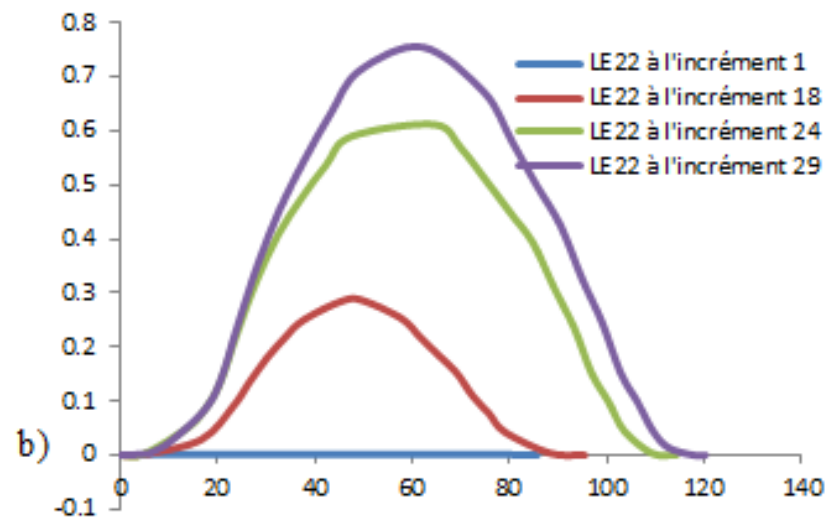

Figure 5. Evolution of stresses (a) and strains (b) for some selected increments

Fig. 5 shows the evolution of stresses and strains for some selected increments. At the first increment (1), strain is still homogeneous and worth 0.002 when the stress reach 268 $\mathrm{MPa}$.

The plastic instability is observed from increasing strain rate up to 0.29 at the increment 18 to become almost heterogeneous at the increment 24 for a value of 0.63 before reaching its maximum value of 0.76 at the last increment (Increment 29) where the stress is increased to $653 \mathrm{MPa}$.

\section{Conclusions}

Tensile tests are important means to release the law and thus the work-hardening coefficient and also to evaluate the plastic deformation instability threshold of the material.

The charge-discharge loop confirms that C35 is work hardening steel.

Burnishing is a mechanical surface treatment known for its beneficial effects it provides to material through plastic deformation of the surface layers. Although the conditions in which it was applied, the treatment did not work-hardens the material, he did start early plastic instability compared to machining.

The simulation of the tensile test provides enough information to locate the necking and it proved to be a good alternative to experimental tests.

\section{REFERENCES}

[1] Hamadache H., Amirat A., Chaoui K. Effect of diamond ball burnishing on surface characteristics and fatigue strength of XC55 steel, Int. Review Mech. Eng. (1) (2008) 40-48.

[2] Avilles R. et al. Influence of low-plasticity ball burnishing on the high-cycle fatigue strength of medium carbon AISI 1045 steel, Int. J. Fatigue (55) (2013) 230-244.

[3] Hamadache H. Laouar L. Chaoui K. Zeghib N. E. Characteristics of $\mathrm{Rb} 40$ steel superficial layer under ball and roller burnishing, J. Mater. Process. Technol. (180) (2006) 130-136.

[4] Yilmaz, S. S., \& Varol, R. The effect of Surface Hardening Treatments on the Mechanical Properties of Iron Based P/M Specimens. Powd Technol, 204, (2010) 236 -240.

[5] Hamadache H. et al. Improvement of surface conditions of 36 Cr Ni Mo 6 steel by ball burnishing process. J MECH SCI TECHNOL 28 (4) (2014) 1491 1498.

[6] Sai W.B., Lebrun J.L. Influence of finishing by burnishing on surface characteristics. J. Mater. Eng. Perform. (12) (2003) $37-40$.

[7] Khalid. S. et al. Effect of Roller Burnishing on the Mechanical Behavior and Surface Quality of O1Alloy Steel. Research J. of Applied Sciences, Eng. and Technology 3 (3) (2011) 227-233.

[8] Gharbi $\mathrm{F}$ et al. Experimental Investigation of the Effect of Burnishing Force on Service Properties of AISI 1010 Steel Plates. J. Mater. Eng. Perform. 24 (2) (2015).721-725.

[9] F. Gharbi et al. Ductility Improvement of Aluminum 1050A Rolled Sheet by a Newly Designed Ball Burnishing Tool Device, Int. J. Adv. Manuf. Technol. (60) (2012) 87-99.

[10] Ozaltun H. et al. An Energy bazed Fatigue Life Prediction Framework for In-service Structural Components. Experimental Mechanics (51) (2011) 707-718.

[11] M. Saboori et al. Extension of flow stress-strain curves of aerospace alloys after necking. Int J Adv Manuf Technol. (83) (2016) 313-323 